\title{
Developing a Molecular Identification Assay of Old Landraces for the Genetic Authentication of Typical Agro-Food Products: The Case Study of the Barley 'Agordino'
}

\author{
Fabio Palumbo, Giulio Galla and Gianni Barcaccia* \\ University of Padova, Department of Agronomy, Food, Natural Resources, Animals and Environment, \\ Viale dell'Università 16, IT-35020 Legnaro (Padova), Italy \\ Received: June 29, 2016 \\ Accepted: November 23, 2016
}

\begin{abstract}
Summary
The orzo Agordino is a very old local variety of domesticated barley (Hordeum vulgare ssp. distichum L.) that is native to the Agordo District, Province of Belluno, and is widespread in the Veneto Region, Italy. Seeds of this landrace are widely used for the preparation of very famous dishes of the dolomitic culinary tradition such as barley soup, bakery products and local beer. Understanding the genetic diversity and identity of the Agordino barley landrace is a key step to establish conservation and valorisation strategies of this local variety and also to provide molecular traceability tools useful to ascertain the authenticity of its derivatives. The gene pool of the Agordino barley landrace was reconstructed using 60 phenotypically representative individual plants and its genotypic relationships with commercial varieties were investigated using 21 pure lines widely cultivated in the Veneto Region. For genomic DNA analysis, following an initial screening of 14 mapped microsatellite (SSR) loci, seven discriminant markers were selected on the basis of their genomic position across linkage groups and polymorphic marker alleles per locus. The genetic identity of the local barley landrace was determined by analysing all SSR markers in a single multi-locus PCR assay. Extent of genotypic variation within the Agordino barley landrace and the genotypic differentiation between the landrace individuals and the commercial varieties was determined. Then, as few as four highly informative SSR loci were selected and used to develop a molecular traceability system exploitable to verify the genetic authenticity of food products deriving from the Agordino landrace. This genetic authentication assay was validated using both DNA pools from individual Agordino barley plants and DNA samples from Agordino barley food products. On the whole, our data support the usefulness and robustness of this DNA-based diagnostic tool for the orzo Agordino identification, which could be rapidly and efficiently exploited to guarantee the authenticity of local varieties and the typicality of food products.
\end{abstract}

Key words: microsatellites, genotyping, landraces, traceability, barley, food authentication

\section{Introduction}

A local variety or landrace is a dynamic and ancient population of a cultivated crop, characterised by a well-established historical and geographical identity, which is locally adapted to the natural resources, agronomic practices of farmers and cultural traditions of consumers (1).
Within the last few decades, interest in local varieties has been renewed primarily because of the rediscovery of traditional local food products and their potential economic value on different market scales.

Among cultivated species, the landraces of barley (Hordeum vulgare L.), a herbaceous plant from the Poaceae 
family that is widely distributed and primarily used for feed, food and malt production, offer a notable case study. Barley is the fourth most important cereal crop in the world, following wheat (Triticum spp.), rice (Oryza spp.) and corn (Zea mays L.). It is cultivated primarily in the temperate regions of Asia, Europe and North America, with a total area of 56 million hectares worldwide and an annual production of 144 million tonnes (2).

The barley landrace Agordino is a two-row local variety of Hordeum vulgare that is widespread in the Veneto Region (Italy) and native to the Agordino District (Belluno). Across the entire dolomitic region, as reported in a nineteenth century manuscript (3), the cultivation of this landrace is a centuries-old tradition. Currently, this landrace survives only in small plots of land totalling a few hectares $1500 \mathrm{~m}$ above sea level, particularly in the municipality of Livinallongo del Col di Lana (the province of Belluno) and in some fields of the Belluno and Feltre Valleys. Morphologically, this barley landrace has very tall stems, normally exceeding $100 \mathrm{~cm}$ in height, and has modest yields (approx. $2.6 \mathrm{t} / \mathrm{ha}$ ) when compared with modern two-row varieties (4). The seeds of this landrace are widely used for the preparation of the barley soup ('zuppa d'orzo'), probably the most famous local dish of the dolomitic culinary tradition. Flour obtained by stone milling of Agordino barley is used for bakery products, such as barley bread and cookies, and roasted seeds are particularly appreciated to produce barley coffee 'caffè d'orzo'). Moreover, some breweries recently started to commercialise lines of beer dedicated to this local variety.

In recent decades, molecular markers have been successfully used not only to characterise and preserve commercial and local barley varieties but also to authenticate raw materials and food derivatives (5). Among the PCR-based techniques, microsatellite or simple sequence repeat (SSR) markers provide a fully codominant and highly polymorphic marker system, widely exploited to implement reproducible and transferable molecular assays, which have found utility in detecting inter- and intra-population differences (6).

In this study, the genetic identity of the Agordino barley landrace has been assessed with SSR markers. As preliminary analysis, we assembled molecular data in order to determine the population genetic structure of the Agordino barley landrace and its genetic relationships with several commercial varieties. Then, we exploited this crucial information to develop a genetic traceability assay of the food products deriving from the Agordino barley landrace. In fact, the most informative SSR marker loci allowed us to determine the most common, highly shared or fixed, marker alleles and varietal genotypes, and to validate marker allele combinations (i.e. multi-locus haplotypes), which are typical and specifically associated with the Agordino barley landrace and, thus, to its food derivatives. The description of the genetic traits of this barley landrace, historically cultivated in the Belluno provincial area, north-eastern Italy, supports a larger adoption of molecular marker analyses for the identification of local materials and the authentication of their seed lots and food derivatives.

\section{Materials and Methods}

\section{Plant material and genomic DNA isolation}

A total of 60 individual samples of the Italian barley landrace Agordino were collected from experimental populations originally collected at different locations across the Belluno province and maintained at the experimental station of the Institute N. Strampelli (Lonigo, VI, Italy), as part of a BIO.NET research project funded by the Rural Development Program of the Veneto Region. Moreover, 35 individual samples belonging to 21 pure lines of the commercial varieties most commonly used by farmers in Veneto were also obtained from the Institute (Table 1), and used as reference standards and test samples. Because the commercial varieties were represented by pure lines and therefore were composed of populations of plants sharing the same genotype, only one or two individuals were analysed for each variety.

Table 1. List of barley samples characterised using molecular markers, including 60 individuals of the Agordino barley landrace and 21 commercial varieties chosen among the most commonly used by farmers in Veneto, Italy, for a total of 95 samples

\begin{tabular}{lclc}
\hline Variety & $N($ sample $)$ & Variety & $N($ sample $)$ \\
\hline Agordino & 60 & Calanque & 1 \\
Concerto & 2 & Casanova & 2 \\
Scarlett & 2 & Cometa & 2 \\
Arda & 2 & Flanelle & 2 \\
Baraka & 2 & Kangoo & 1 \\
Barberusse & 2 & Marjorie & 1 \\
Plaisant & 2 & Sfera & 1 \\
Leonessa & 2 & Alba & 1 \\
Saxsonia & 2 & Scandella & 2 \\
Atomo & 2 & Tunika & 1 \\
Braemar & 2 & Primus & 1 \\
\hline
\end{tabular}

Genomic DNA was isolated from $100 \mathrm{mg}$ of fresh leaf tissue using a DNeasy plant kit (Qiagen, Valencia, CA, USA), following the procedure provided by the supplier. The integrity of extracted DNA samples was estimated by electrophoresis on a $0.8 \%$ agarose $/ 1 \times$ TAE gel containing $1 \times$ SYBR Safe DNA stain (Life Technologies, Carlsbad, CA, USA). Both the purity and quantity of DNA extracts were assessed with a NanoDrop 2000c UV-Vis spectrophotometer (Thermo Scientific, Pittsburgh, PA, USA).

\section{Analysis of SSR markers}

To genotype the 95 barley samples, PCR amplifications and microsatellite (SSR) marker analyses were performed using the M13-tailed SSR method described by Schuelke (7), with some modifications. An M13-labelled primer (5'-TTGTAAAACGACGGCCAGT-3') was used in combination with a specific SSR-targeting forward primer with a 5'-M13 tail and a specific SSR-targeting reverse primer.

The set of 14 SSR marker loci investigated in this study was obtained from Varshney et al. (8). An initial screening of a subset of 12 DNA samples, randomly cho- 
sen among the local and commercial varieties, was performed to investigate the amplification efficiency and polymorphism information content of the chosen SSR markers (Table 2). One SSR marker locus per linkage group was then selected for the genotyping of all DNA samples, including Bmag0872, Bmag0125, EBmac0871, Bmag0808, EBmatc0003, Bmac0727 and Bmag0321 (8).

The PCR reaction mixture had a final volume of $20 \mu \mathrm{L}$ and contained $1 \times$ Platinum ${ }^{\circledR}$ Multiplex PCR Master Mix, $10 \%$ GC Enhancer (Applied Biosystems, Carlsbad, CA, USA), $0.25 \mu \mathrm{M}$ of each tailed primer, $0.75 \mu \mathrm{M}$ of each reverse primer, $0.5 \mu \mathrm{M}$ of each labelled primer (Applied Biosystems), $10 \mathrm{ng}$ of DNA and distilled water. Amplifications were performed using a 9600 thermal cycler (Applied Biosystems) with a 96-well plate under the following conditions: $2 \mathrm{~min}$ at $95^{\circ} \mathrm{C}$, followed by 5 cycles at 95 ${ }^{\circ} \mathrm{C}$ for $30 \mathrm{~s}$ and at $60{ }^{\circ} \mathrm{C}$ for $90 \mathrm{~s}$, which decreased by $0.8^{\circ} \mathrm{C}$ with each cycle, and at $72{ }^{\circ} \mathrm{C}$ for $45 \mathrm{~s}$, then 30 cycles at 95 ${ }^{\circ} \mathrm{C}$ for $30 \mathrm{~s}$, at $56{ }^{\circ} \mathrm{C}$ for $90 \mathrm{~s}$, and at $72{ }^{\circ} \mathrm{C}$ for $45 \mathrm{~s}$. The reaction was terminated with a final extension of $10 \mathrm{~min}$ at 72 ${ }^{\circ} \mathrm{C}$. The PCR products were then subjected to capillary electrophoresis with an ABI PRISM 3130xl Genetic Analyzer (Applied Biosystems). The LIZ500 was adopted as molecular mass standard. Finally, the size of each peak was determined using Peak Scanner ${ }^{\mathrm{TM}}$ software v. 1.0 (9).

\section{Marker analysis}

To estimate the marker allele variation of the selected SSR loci in the 95 barley accessions, the polymorphism information content (PIC) was calculated using PICcalc software (10). This index provides an estimate of the discriminating power of each co-dominant marker locus and it depends on the number of detectable marker alleles and on the distribution of their frequency.

Marker allele frequencies computed for the Agordino population were used to estimate the genetic diversity and differentiation statistics using the POPGENE software v. 1.32 (11). The average number of alleles observed per locus $\left(N_{\mathrm{a}}\right)$ and the effective number of alleles per locus $\left(N_{\mathrm{e}}\right)$ were calculated according to Kimura and Crow (12). For each marker locus and for all loci, the Nei's genetic diversity (13) of the Agordino landrace, which corresponds to the Nei's expected heterozygosity $(\mathrm{H})$, was computed as:

$$
\mathrm{H}=1-\Sigma \mathrm{p}_{\mathrm{i}}^{2}
$$

where $p_{i}$ is the population frequency of the ith marker allele. The polymorphism degree was calculated using Shannon's information index (I) of phenotypic diversity as follows (14):

$$
\mathrm{I}=-\Sigma \mathrm{p}_{\mathrm{i}}^{2} \ln \mathrm{p}_{\mathrm{i}}^{2}
$$

Genetic similarity between individuals of the local and commercial accessions in all possible pairwise comparisons was estimated by applying the coefficient of simple matching. Differently from other statistics used to assess the genetic similarity between individuals, the simple matching coefficient, also known as Rohlf's coefficient (15), takes into account not only shared and polymorphic marker alleles, but also marker alleles missing in both samples under comparison and present in other samples of the same population as factors that contribute to the similarity estimates among pairwise combinations of individuals. The ordination analysis was performed according to the unweighted pair-group method with arithmetic mean (UPGMA), and the dendrogram and centroids of all accessions were constructed from the mean genetic similarity matrix. Principal coordinate analysis (PCoA) was applied to compute the first two principal components of the qualitative data matrix. All calculations and analyses were conducted using NTSYS-pc v. 2.21q software (15). A bootstrap statistical analysis was conducted to measure the stability of the computed branches with 1000 resampling replicates.

Table 2. Information on the simple sequence repeat (SSR) marker loci analysed in this study, including linkage group, locus name, primer sequence and amplicon size. The polymorphism information content (PIC) value is also reported for each locus (8). Loci writ-

\begin{tabular}{|c|c|c|c|c|c|}
\hline $\begin{array}{l}\text { Linkage } \\
\text { group }\end{array}$ & Locus & Forward & Reverse & Size/bp & PIC \\
\hline $1 \mathrm{H}$ & Bmag0872 & ATGTACCATTACGCATCCA & GAAATGTAGAGATGGCACTTG & $125-153$ & 0.81 \\
\hline $1 \mathrm{H}$ & Bmag0211 & GCAAGCTTCCTAAATCCTTA & TGCAGACAGTTTTTCATATACA & $174-220$ & 0.83 \\
\hline $2 \mathrm{H}$ & Bmag0125 & AATTAGCGAGAACAAAATCAC & AGATAACGATGCACCACC & 138-157 & 0.76 \\
\hline $2 \mathrm{H}$ & EBmac0415 & GAAACCCATCATAGCAGC & AAACAGCAGCAAGAGGAG & $247-282$ & 0.58 \\
\hline $3 \mathrm{H}$ & EBmac0871 & TGCCTCTGTTGTGTTATTGT & CCCCAAGTGAACATTGAC & 194-211 & 0.83 \\
\hline $3 \mathrm{H}$ & Bmac0127b & AACTATGTCCAGTCGTTTCC & CTTGTCGTATCATCTTATTCAGA & 118 & 0.67 \\
\hline $4 \mathrm{H}$ & Bmag0808 & TCATAGACTACGACGAAGATG & TCTTTGGATGTGTGTTTACTG & 199-209 & 0.84 \\
\hline $4 \mathrm{H}$ & Bmag0490 & TGATACATCAAGATCGTGACA & GGGACTGAGTGTATGAATGAG & 121 & 0.73 \\
\hline $5 \mathrm{H}$ & EBmatc0003 & AATTTTGCAAAGCTGGAGG & CATTATGGTGGGGTTCATGT & 113-129 & 0.60 \\
\hline $5 \mathrm{H}$ & EBmac0824 & ATTCATCGATCTTGTATTAGTCC & ACATCATGTCGATCAAAGC & $308-371$ & 0.43 \\
\hline $6 \mathrm{H}$ & Bmac0727 & AACTATGTCCAGTCGTTTCC & CTTGTCGTATCATCTTATTCAGA & 126-140 & 0.83 \\
\hline $6 \mathrm{H}$ & Bmag0613 & AAGAACACCATATGATCCAAC & CTCCATGACTATGAGGAGAAG & $171-218$ & 0.73 \\
\hline $7 \mathbf{H}$ & Bmag0321 & АTTATCTCCTGCAACAACCTA & CTCCGGAACTACGACAAG & $230-243$ & 0.70 \\
\hline $7 \mathrm{H}$ & Bmag0206 & TTTTCСССТATTATAGTGACG & TAGAACTGGGTATTTCCTTGA & 239 & 0.79 \\
\hline
\end{tabular}
ten in bold were the ones assayed in this study 
The genetic structure of the Agordino landrace and of the entire barley core collection based on a total of 95 DNA samples, including the individuals of the local population and commercial materials (i.e. pure lines), was also modelled using a Bayesian clustering algorithm implemented in STRUCTURE v. 2.2 software (16). Since barley (Hordeum vulgare L.) plants strictly reproduce by self-pollination and cultivated populations are composed of highly homozygous individuals, a haploid setting was used for this analysis. Using the admixture model with independent allele frequencies, ten replicate simulations were conducted for each value of number of populations $(\mathrm{K})$, with $\mathrm{K}$ ranging from 1 to 20 , using a burn-in of $2 \cdot 10^{5}$ and final run of $10^{6}$ Markov chain Monte Carlo (MCMC) steps (17). The method described by Evanno et al. (18) was used to evaluate the most probable estimation of $\mathrm{K}$.

\section{Developmental validation tests}

Genotypic data from all Agordino individuals showing a membership higher than $75 \%$, as assessed by STRUCTURE v. 2.2 software (16), were used to identify the population-specific marker alleles at each locus and the frequency of the multi-locus haplotypes of the landrace. SSR loci showing at least one typical marker allele were selected for the validation procedure. Marker alleles were scored as 'typical' when present and shared by $100 \%$ of the Agordino individuals and absent from the commercial varieties or with a frequency lower than $5 \%$.

For the validation study, three blends were prepared by combining genomic DNA of a randomly chosen Agordino genotype (sample OA23) with genomic DNA of a given commercial variety (namely 'Arda') in three different ratios: 1:1, 1:2 and 1:10. All DNA samples were then screened at the selected SSR marker loci in order to verify the detection of Agordino and non-Agordino marker alleles in experimental pooled conditions. In addition, genomic DNA extracted using cetyltrimethylammonium bromide (CTAB) method (19) from two commercial products of the Agordino barley, including barley seeds for soup preparation (Cooperativa Agricola La Fiorita, Cesiomaggiore BL, Italy) and barley crackers (Cooperativa Agricola La Fiorita), were analysed at the same SSR marker loci.

\section{Results}

\section{Descriptive statistics of SSR marker loci}

Levels of genetic variability among landrace individuals and commercial pure lines were high (Table 3). The polymorphism information content (PIC) value of the seven SSR marker loci chosen for the genotyping analysis was on average equal to 0.62 , ranging from 0.50 (EBmatc0003 ) to 0.71 (Bmag0125). All the examined loci were polymorphic across all barley accessions, and the most common marker allele had a frequency of 0.60 (Ebmac0871).

Descriptive statistics of all SSR loci, in addition to the level of genetic diversity found across molecular markers and plant accessions, are reported in Table 3. In the barley populations, a total of 41 marker alleles were detected, and the average number of observed alleles $\left(N_{\mathrm{a}}\right)$ per SSR locus was equal to 5.86 for all accessions, with numbers
Table 3. Descriptive statistics of genetic diversity calculated across markers and barley accessions. Included are the frequency of the most common marker allele $\left(p_{i}\right)$, average number of observed alleles $\left(N_{\mathrm{a}}\right)$ and of effective number of alleles $\left(N_{\mathrm{e}}\right)$ per locus, level of observed homozygosity $\left(\mathrm{H}_{\mathrm{o}}\right)$, and estimates of Shannon's information index of phenotypic diversity (I) and unbiased Nei's genetic diversity $(\mathrm{H})$. The polymorphism information content (PIC) coefficient was calculated for each locus. The overall values and standard deviations (S.D.) are also reported for each parameter

\begin{tabular}{lccccccc}
\hline Locus ID & $\mathrm{p}_{\mathrm{i}}$ & $\mathrm{N}_{\mathrm{a}}$ & $\mathrm{N}_{\mathrm{e}}$ & $\mathrm{H}_{\mathrm{o}}$ & $\mathrm{I}$ & $\mathrm{H}$ & $\mathrm{PIC}$ \\
\hline Bmag0872 & 0.45 & 7.00 & 3.54 & 1.00 & 1.49 & 0.72 & 0.68 \\
Bmag0321 & 0.55 & 6.00 & 2.55 & 1.00 & 1.20 & 0.61 & 0.55 \\
Bmag0808 & 0.33 & 5.00 & 3.65 & 1.00 & 1.38 & 0.73 & 0.68 \\
Bmac0727 & 0.43 & 7.00 & 3.88 & 1.00 & 1.60 & 0.74 & 0.71 \\
EBmac0871 & 0.60 & 6.00 & 2.42 & 1.00 & 1.16 & 0.59 & 0.54 \\
EBmatc0003 & 0.59 & 3.00 & 2.30 & 1.00 & 0.96 & 0.56 & 0.50 \\
Bmag0125 & 0.34 & 7.00 & 4.03 & 1.00 & 1.53 & 0.75 & 0.71 \\
\hline Agordino & 0.93 & 3.86 & 2.13 & 1.00 & 0.84 & 0.45 & \\
Commercial & 0.82 & 4.43 & 2.78 & 1.00 & 1.13 & 0.60 & \\
\hline Mean value & 0.53 & 5.86 & 3.20 & 1.00 & 1.33 & 0.67 & 0.62 \\
S.D. & 0.19 & 1.46 & 0.75 & 0.00 & 0.23 & 0.08 & 0.09 \\
\hline
\end{tabular}

that ranged from three to seven. In further detail, the average number of alleles per SSR locus was 3.86 for the Agordino landrace, whereas the mean was 4.43 for the set of commercial varieties. Moreover, the effective number of alleles $\left(N_{\mathrm{e}}\right)$ per SSR locus was 2.13 and 2.78 for the landrace and for the pure lines overall, respectively.

Estimates of both unbiased Nei's genetic diversity $(\mathrm{H})$ and Shannon's information index of phenotypic diversity (I) were used to characterise the gene pools of the Agordino landrace and the commercial varieties (Table 3). The mean genetic diversity for all marker loci was 0.67 (S.D.= 0.08 ) and ranged from the minimum of 0.56 (locus EBmatc0003) to the maximum of 0.75 (locus Bmag0125). The measures of molecular genetic diversity were 0.45 and 0.60 for the Agordino landrace and the commercial varieties, respectively. Shannon's information index (I) for all marker loci was 1.33 (S.D.=0.23) and ranged from the minimum of 0.96 (locus EBmatc0003) to the maximum of 1.60 (locus Bmac0727). This information index of marker phenotypic diversity was higher in the commercial accessions (1.13) than in the Agordino accessions (0.84; see Table 3). Finally, the Agordino landrace included a mixture of pure lines that were $100 \%$ homozygous but for different marker alleles at one or more genomic loci. Each of the commercial varieties was shown to correspond to a single pure line and all these genetically different lines scored a homozygosity level of $100 \%$, as expected (Table 3).

\section{Genetic diversity and cluster analysis}

Genetic variability within and between varieties was investigated primarily by calculating genetic similarity estimates for all possible pairwise comparisons among the 95 DNA samples/genotypes using the entire set of marker alleles scored at all genomic loci. In particular, a pairwise genetic similarity matrix was calculated using a simple matching coefficient. Rohlf's genetic similarity ranged 
from 61 to $100 \%$ in the landrace population, with an average of $84 \%$, and the identical index varied from 60 to $100 \%$, with an average of $78 \%$, for the commercial varieties as a group. Between commercial varieties and the individuals of the Agordino landrace, genetic similarity values ranged between 50 and $90 \%$, with an average of $69 \%$.

Both ordination methods (UPGMA tree and PCoA centroids) based on the genetic similarity estimates identified two subgroups of individuals (Figs. 1 and 2). Moreover, all 95 genotypes were divided into two major clusters, supported by a bootstrap value of $100 \%$, and most Agordino accessions were clustered into one well-defined major group, as shown in Fig. 1. Most notably, the Agordino individuals contained at least 16 genetically different pure lines that were split into four subclusters, with bootstrap values ranging from 90 to $100 \%$. Some of these pure lines were apparently overrepresented and comprised up to a dozen individuals each. The second major cluster included all commercial pure lines and four Agordino individuals (i.e. OA30, OA46, OA50 and OA52).

Principal coordinate analysis (PCoA) defined the centroids for all barley accessions, with the two-dimensional plot shown in Fig. 2. Based on the marker alleles, the first principal coordinate accounted for $77.4 \%$ of the total variation and clearly separated the local genotypes from the commercial ones. In addition, consistently with the UPGMA tree, four distinct subclusters were formed for the Agordino landrace population using PCoA, with few individuals whose centroids were closely related to those of the commercial pure lines. The genotype of the commercial variety Alba proved to be very similar to that of some individuals of the local variety Agordino (see Figs. 1 and
2). This finding was further supported by a mean genetic similarity value of 0.81 from the pairwise comparison between the Alba accession and the Agordino population as a whole.

\section{Genetic structure analysis}

Based on the marker alleles at all SSR loci, the genetic structure of the barley core collection was investigated using STRUCTURE v. 2.2 software (16). Following the procedure of Evanno et al. (18), examination of the population structure by estimation of $\Delta \mathrm{K}$ values was consistent with the partitioning of the population into two genetically distinguishable subgroups (Fig. 3), confirming the results from UPGMA analyses. In particular, the 95 barley samples were partitioned into two major marker allele clusters or ancestral multilocus haplotypes. For each plant accession, a vertical histogram was portioned into $\mathrm{K}=2 \mathrm{col}-$ oured segments to represent the estimated membership of each hypothesised ancestral genotype. Single plant accessions were sorted by population type, and the clustering of individuals revealed only a few admixed accessions, such as OA20, OA38, OA44 (local variety) and Alba as commercial variety (see Fig. 3), with membership values that ranged from 43 to $64 \%$. As the most dominant feature of the output, almost all individuals of the local landrace shared the same marker allele cluster, with accession scores of individual membership that were almost always higher than $94 \%$. By contrast, the apparently heterogeneous group of 21 commercial varieties was dominated by a single genetic pattern, providing strong support for these pure lines as a separate population with a distinct genetic background sharing a unique ancestry. Fi-

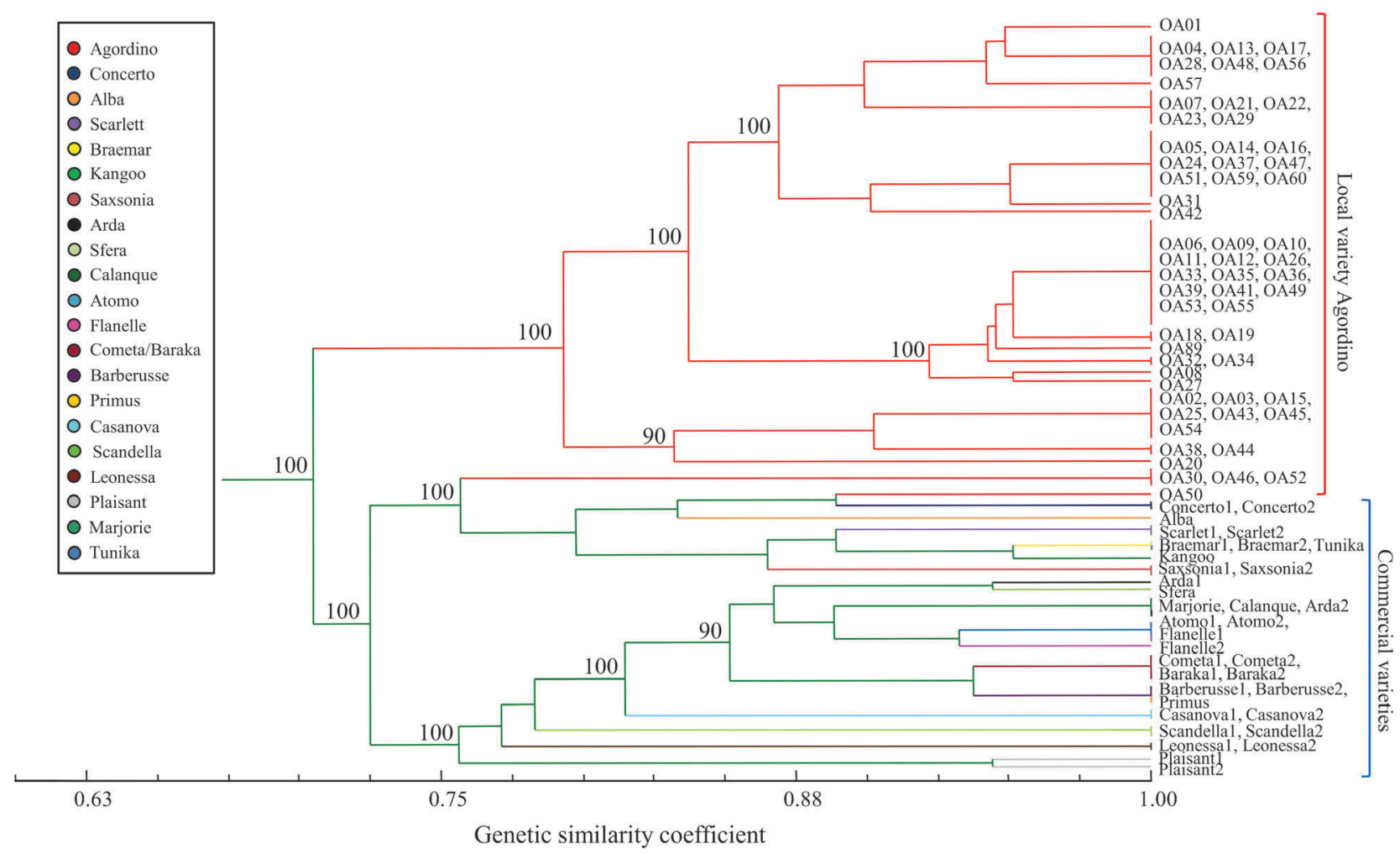

Fig. 1. Unweighted pair-group method with arithmetic average mean (UPGMA) tree of the genetic similarity estimates computed among pairwise comparisons of barley accessions using the whole simple sequence repeat (SSR) marker data set, with nodes of the main subgroups supported by bootstrap values 


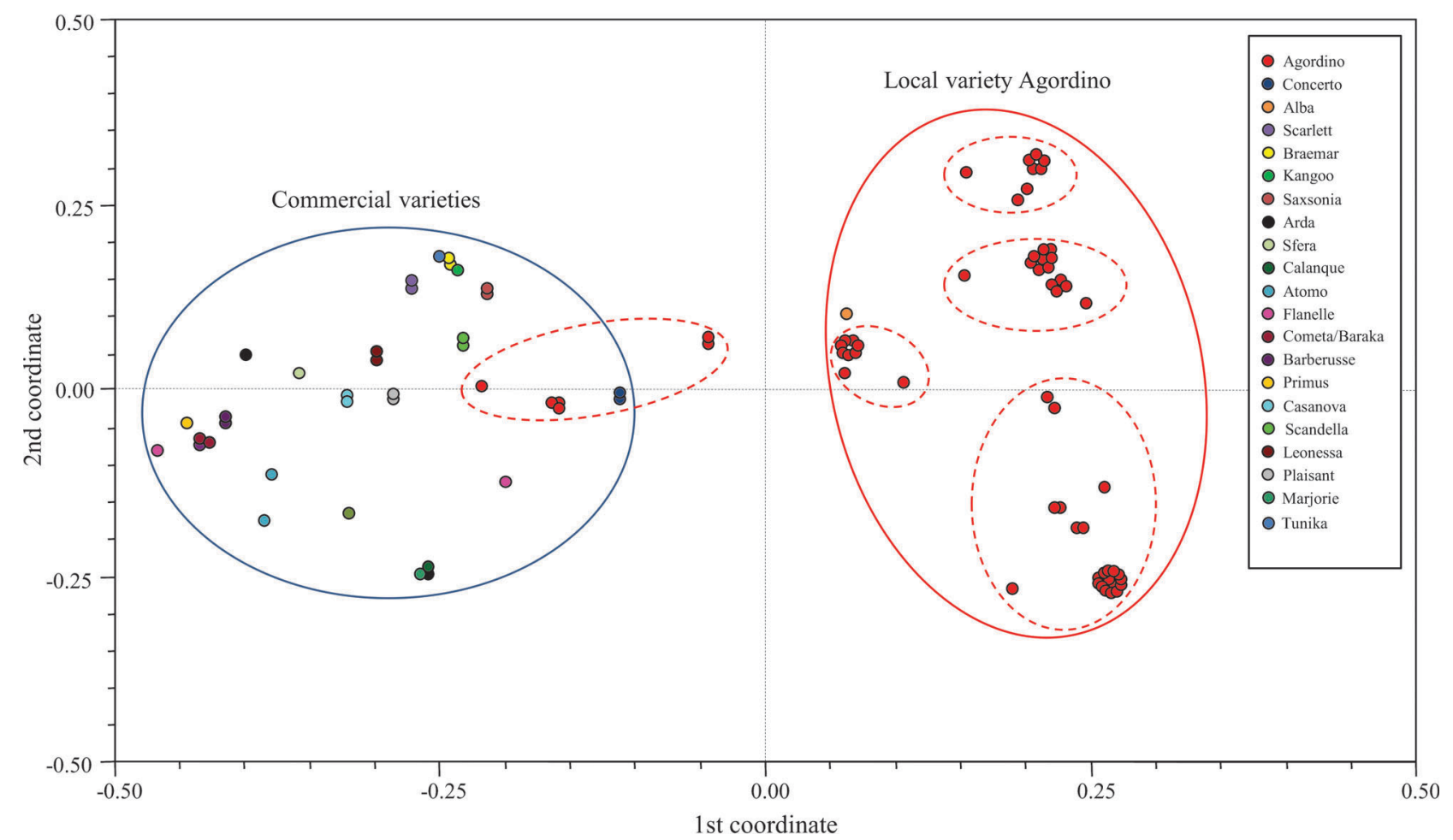

Fig. 2. Two-dimensional centroids derived from the genetic similarity estimates computed among barley accessions in all possible pairwise comparisons using the whole simple sequence repeat (SSR) marker data set. Two main subgroups are distinguishable, one including most of the Agordino individuals, with a few exceptions, and the other containing all but one (Alba) commercial lines

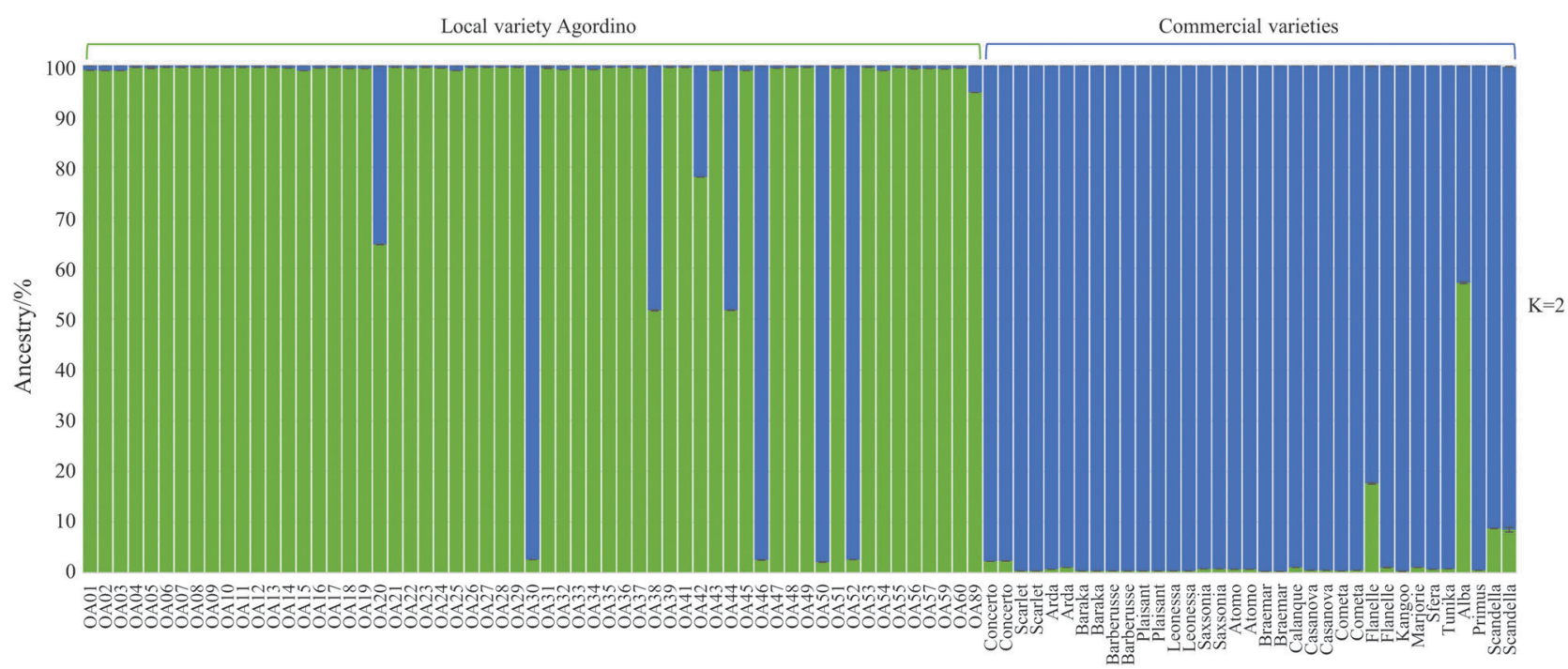

Fig. 3. Population genetic structure of the Agordino landrace individuals $(N=60)$ and the commercial varieties $(N=35)$ as estimated by STRUCTURE v. 2.2 software (16) using whole simple sequence repeat (SSR) marker data set. Each sample is represented by a vertical histogram partitioned into $\mathrm{K}=2$ coloured segments that represent the estimated membership. The proportion of ancestry (\%) is reported on the ordinate axis (the identification number of each accession is reported below each histogram)

nally, four local samples (i.e. OA30, OA46, OA50 and OA52) grouped closely with the cluster of commercial varieties.

\section{Genetic authentication assay}

In order to implement a genetic authentication assay, based on the genetic structure analysis, seven samples scoring a membership lower than $75 \%$ to the founding group of the Agordino landrace (namely OA20, OA30, OA38, OA44, OA46, OA50 and OA52) were removed from further analysis because they were attributable to deviant or admixed haplotypes. The marker allele composition and proportion at each locus for the local population of Agordino barley is reported in Fig. 4. Eight Agordino-specific marker alleles, defined as typical of this landrace because never detected in the commercial lines (Fig. 4), were iden- 


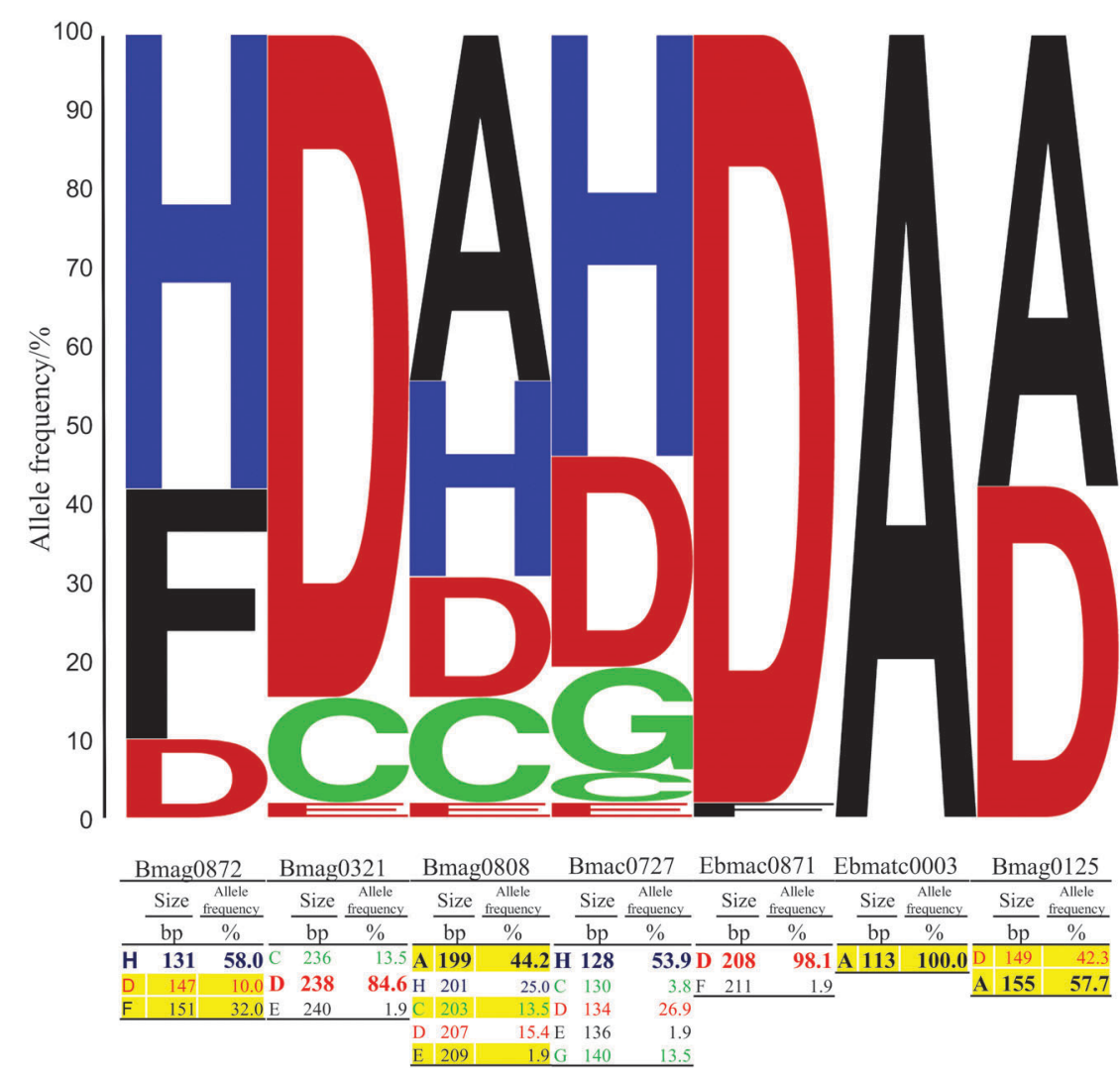

Fig. 4. Graphical representation of the marker allele type and frequency at each SSR locus for the Agordino landrace. Each stack represents a locus and the height of letters within each stack indicates the relative frequency of the corresponding alleles. The correspondence between letters, allele sizes (bp) and frequencies (\%) at each locus is reported in the table under the chart. For each locus, the most common allele is written in bold, whereas the typical alleles of the landrace are highlighted in yellow

tified at four SSR loci, namely Bmag0872, Bmag0808, EBmatc0003 and Bmag0125. An explanatory example for two of these loci is shown in Fig. 5. Using the three blends of genomic DNA samples, the molecular phenotype (i.e. marker genotype) attributed to the Agordino germplasm (sample OA23, marker alleles of 199 and 155 bp) is clearly distinguishable from that of the commercial variety (line Arda, marker alleles of 201 and 157 bp), even when the concentration of the local variety is tenfold lower than the concentration of the commercial variety (see Figs. 5c and f).

Developmental validation tests were also performed successfully using commercial Agordino-based food products. Marker allelic profiles at the four informative loci using genomic DNA extracted from two commercial food products (i.e. barley seeds for soup preparation and barley crackers, respectively) as template for SSR amplifications are reported in Fig. 6. For each locus, several marker alleles were detected but only some of them could be unambiguously assigned to the Agordino gene pool. It is worth mentioning that some of the marker alleles could not be univocally associated with the local variety because they were identified also in some of the commercial lines (Fig. 6).

\section{Discussion}

The genetic identity and population structure of the Agordino landrace was assessed as preliminary goal to acquire essential information for the development of a molecular traceability assay of food products. This research reports original findings from the first analysis of the genetic diversity and identity of the old Italian landrace of barley locally named Agordino. On the basis of these findings, our goal was that of selecting a set of markers useful for the identification of plant materials and the authentication of commercial food products labelled as Agordino. The commercial varieties used as reference standards were chosen among those most grown by farmers in the Veneto region and were used to assess the intra- and inter-population genetic variation and to reconstruct the genetic structure of the population as a whole.

For the purposes of this analysis, an initial screening was performed by using the 14 SSR markers selected from the work of Varshney et al. (8). SSR markers were amplified and their PIC values assessed using a subset of samples belonging to both the local and the commercial varieties. Following this initial screening, the selection of the most suitable SSR markers was based on the following criteria: (i) genetic mapping of the marker loci in different linkage groups, (ii) lack of non-specific amplicons, (iii) electropherograms showing unambiguous peaks, (iv) ability to be amplified in multiplex reactions, and $(v)$ absence of null alleles. As a result, seven markers were selected for the multilocus genotyping: Bmag0872, Bmag0125, EBmac0871, Bmag0808, EBmatc0003, Bmac0727 and Bmag0321 (8). 

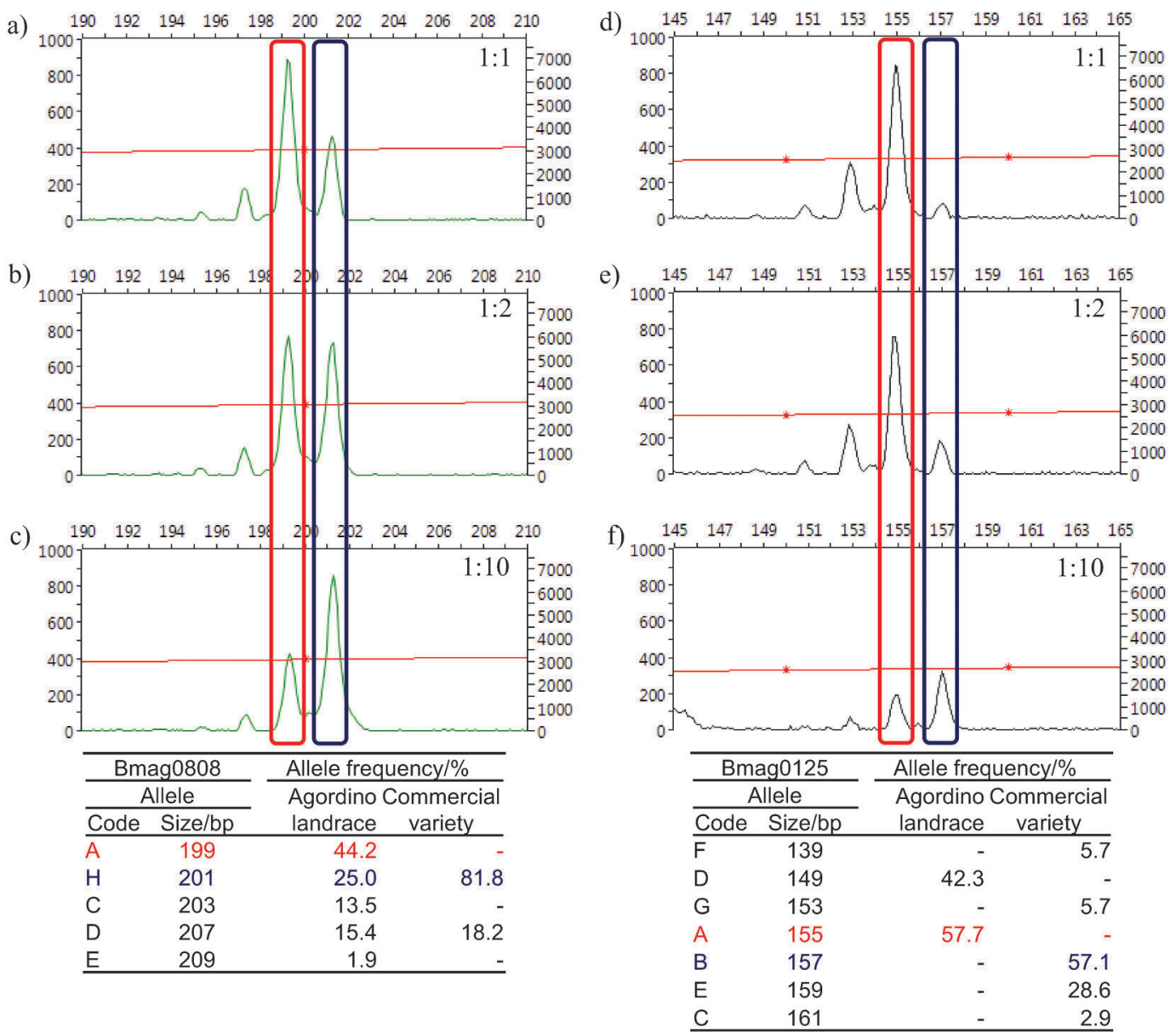

Fig. 5. Electropherograms of microsatellite amplicons at loci Bmag0808 (a-c) and Bmag0125 (d-f) related to an experimental blend prepared by combining genomic DNA from an Agordino individual and the commercial variety Arda in three different ratios: 1:1 (a and d), 1:2 (b and e) and 1:10 ( $\mathrm{c}$ and f). Rectangles highlight the marker alleles belonging to Agordino (red) and to Arda (blue). Tables report the correspondence among letters, allele sizes (bp) and allele frequencies (\%) both in the Agordino population and the commercial group. Plots of the dye signal traces were obtained by Peak Scanner ${ }^{\mathrm{TM}}$ software v. 1.0 (9)

The Agordino landrace scored a relatively high number of marker alleles among its individuals and the population on the whole proved to be composed of a mixture of closely related genotypes belonging to distinct pure lines, although homozygous for different marker alleles at the investigated genomic loci (i.e. the degree of homozygosity was $100 \%$ for all individuals). In fact, most likely these pure lines, although cultivated one next to the other, remain reproductively independent and therefore provide phenotypically homogenous progenies while maintaining substantial genetic variability among the pure lines.

The molecular marker-based genotyping is known to be accurate and effective in identifying the genetic signatures of crop varieties. In previous population genetic studies on barley, 10 to 20 SSR marker loci were analysed (20-23), whereas in this study the number of SSR marker loci was progressively reduced from 14 to 7 and then to four for genetic traceability purposes. Although it is difficult to define an ideal or standard number of microsatellite regions to test in a given species, the number of microsatellite markers depends on several factors, including the polymorphism information content of each target locus, the number of plant accessions and type of plant populations, and especially the goals of the genetic char- acterisation. In this study, only one highly representative and informative SSR marker was selected for each of the linkage groups of barley and almost all individuals collected as Agordino could be unambiguously assigned to the landrace, on the basis of multilocus genotypes. Our findings demonstrate that the chosen SSR markers were highly efficient in revealing the genetic diversity and in assessing the genetic identity of the germplasm of barley accessions.

With the UPGMA grouping analyses, a reliable representation of the results was provided: the accessions were all clustered, with the strongest bootstrap support (100 $\%$ ), into two genetically distinct subgroups, which were formed by the Agordino landrace individuals and by the commercial lines, respectively. The clear separation of the Agordino population into four or more different subgroups is consistent with a self-pollinating species likely composed of a mixture of genotypically similar but reproductively independent pure lines. Only a few samples of Agordino landrace (i.e. OA30, OA46, OA50 and OA52) scored low levels of genetic similarity compared with the rest of the individuals. Notably, these deviant genotypes of Agordino were tightly grouped along with some commercial varieties (see, for instance, Figs. 1 and 2). This re- 

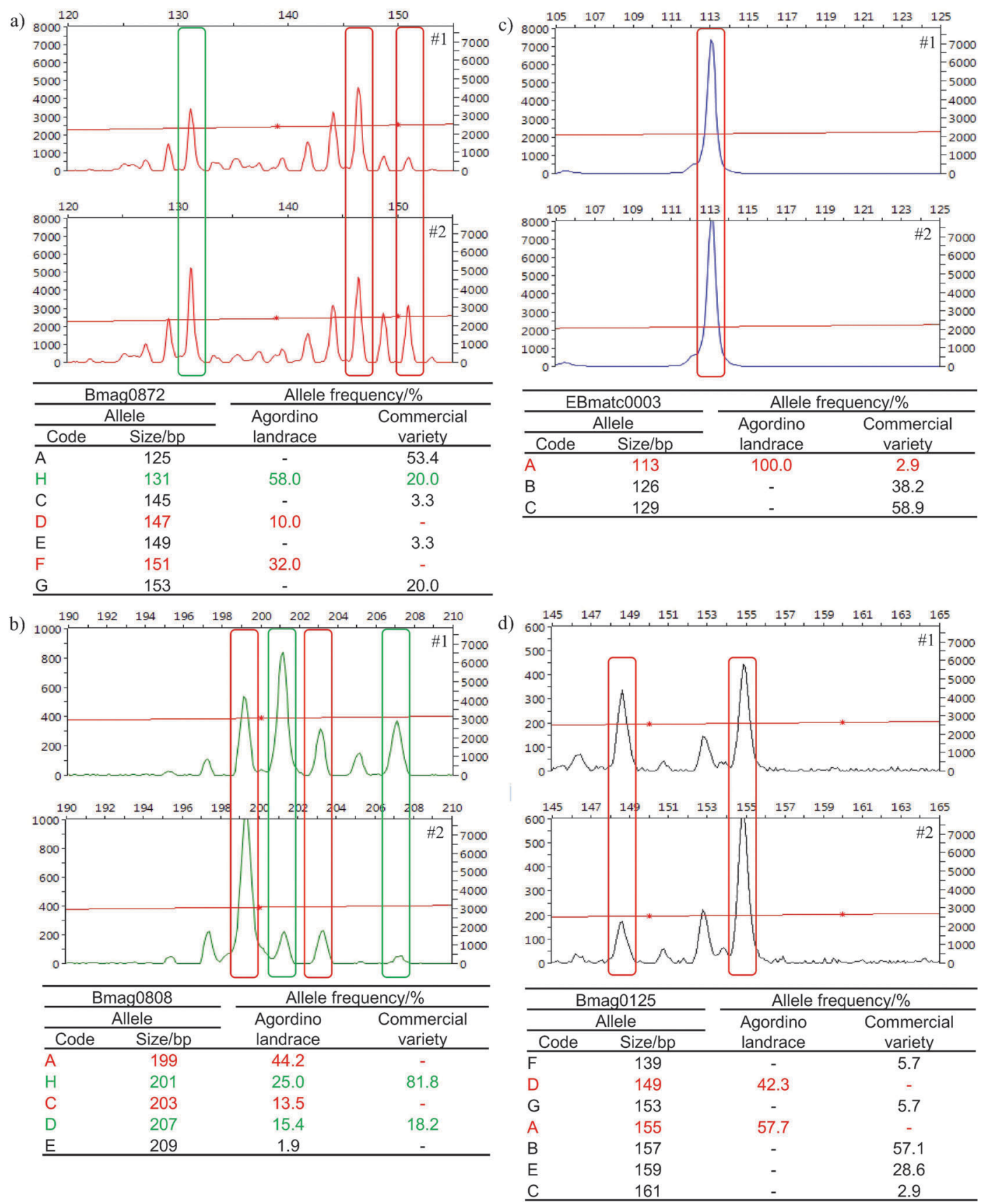

Fig. 6. Electropherograms of microsatellite amplicons at four loci: a) Bmag0872, b) Bmag0808, c) EBmatc0003 and d) Bmag0125 of genomic DNA extracted from two commercial food products deriving from Agordino, i.e. barley seeds for soup preparation (sample \#1) and barley crackers (sample \#2). Rectangles highlight the marker alleles unambiguously associated with the Agordino landrace, defined as typical (red), and the marker alleles shared with commercial varieties (green). Tables report the correspondence among letters, allele sizes (bp) and allele frequencies (\%) both in the Agordino population and the commercial group. Plots of the dye signal traces were obtained by Peak Scanner ${ }^{\mathrm{TM}}$ v. 1.0 software (9)

sult suggests that seeds from commercial varieties might have been accidentally bulked with Agordino materials. Our findings also support the possibility that some individual plants of the local variety might have been used to breed commercial varieties. For instance, the high mean genetic similarity value ( $>86 \%$ ) scored by the pure line Alba with Agordino individuals indicates that local materials might have contributed to the development of this commercial variety. Very scarce information is available for this variety. It is known that Alba is a variety bred for the ability of its malted grains for brewing and it is cultivated in Italy since the 1970s (24). Actually, this variety is not officially recorded in the national register of cultivated varieties and, to the best of our knowledge, there are no records about its ancestry.

Consistent with these findings, the detailed investigation using STRUCTURE v. 2.2 software (16) showed that the 95 samples were separated into two genetically distinct subgroups $(\mathrm{K}=2)$ : most of the 60 analysed individuals of Agordino and the 21 commercial pure lines. Addi- 
tionally, most of the samples (87 of 95) were assigned to either of the groups with accession scores for individual membership that were almost always higher than $95 \%$ (with the exception of the four samples with values that ranged from 78 to $91 \%)$. Based on this analysis, the Agordino population was homogeneous for high ancestry assignation. It is worth noting that the four Agordino individuals showing a membership higher than $95 \%$ to the commercial group (i.e. OA30, OA46, OA50 and OA52) exhibited also the lowest mean genetic similarity values with the Agordino landrace, grouping closely to the commercial lines (see, for instance, Figs. 1 and 2). These findings supported the hypothesis that seeds from commercial varieties might have been accidentally bulked with Agordino materials.

Four samples, i.e. OA20, OA38, OA44 and the pure line Alba, had admixed ancestry, with membership values that varied from 43 to $65 \%$. The admixed ancestry of the Alba variety (43\%) suggested that this commercial line was developed from an ancestor of the local Agordino variety. By contrast, for the admixed samples of Agordino landrace (i.e. OA20, OA38 and OA44), we speculate that hybridization with commercial varieties could have occurred with important effects on the genetic structure of the landrace.

An attempt to increase the genetic distinctiveness and stability of this very old landrace still grown in Veneto has been done by taking advantage of the genetic structure data here presented. In particular, the samples characterised by a membership lower than $75 \%$ (i.e. OA20, OA30, OA38, OA44, OA46, OA50, OA52) were removed and the population was multiplied using the seed set from the rest of individuals.

Concerning the need to implement a genetic authentication assay for the Agordino barley, the genotyping of all individuals allowed the identification of typical marker allele variants for this landrace. Based on these data, the most informative loci proved to be Bmag0872 (typical alleles D and F), Bmag0808 (typical alleles A, C and E), EBmatc0003 (typical allele A) and Bmag0125 (typical alleles A and D). These four SSR markers were successfully used not only to recognise and differentiate the local variety from other commercial varieties, but also to genetically trace its derived food products. Nevertheless, we do not exclude the possibility to investigate additional genomic loci to increase the number of Agordino-specific markers. The finding that typical marker alleles of Agordino could be unambiguously detected in experimental blends assembled by imposing up to tenfold dilutions of the target DNA (see Fig. 5) indicates that the molecular identification assay is suitable to trace DNA from Agordino barley in a wide range of applications and products.

Since mislabelling is recognised as a significantly growing problem in food chains, our data indicate that a few chosen SSR markers are sufficient, when used in combination, to discriminate food products entirely prepared with traditional/local varieties from the ones blended with commercial ones. Furthermore, based on these data, we are planning to further investigate whether it is possible to correlate the intensity of amplified marker allele variants with the relative proportion of target varieties in a mixture.
Molecular data deriving from the amplification of genomic DNA extracted from two commercial Agordino-based food products revealed high levels of complexity as expected considering the high degree of genetic diversity found within the Agordino gene pool. Indeed, while several peaks were detected at each locus, only some of them (see Fig. 6) could be unambiguously associated with the Agordino gene pool. Hence, crosschecks of data originating from the analysis of multiple SSR marker loci may be recommended, if not necessary, to efficiently capture the target marker alleles within the Agordino gene pool.

Based on our findings, the food products examined here seem to be entirely prepared with accessions of barley ascribable to the Agordino landrace, as stated on the food label. Despite the common origin of the two Agordino food products, significant differences in terms of peak intensities were found between them, suggesting that multiple genotypes and variable dosages of the same genotypes may have been adopted for the preparation of the two commercial products. Since qPCR is a more efficient approach to estimate the quantitative contribution of each genotype in the preparation of the commercial products, it could be employed as a future perspective.

\section{Conclusions}

Landraces that remain locally dominant in regional agriculture systems and, in particular, crop plant populations that have characterised a territory for a long time must be safeguarded, and the cultural heritage and the landscape linked to the crop must be preserved. This study is the first detailed genetic characterisation and description of the Agordino landrace of barley, an ancient and traditional variety widespread across the Belluno provincial area (Veneto, Italy) and widely used for the preparation of premium products sold locally.

An important result of this study is that the old Italian local variety of barley cultivated in the region of Agordo is represented by a small and well-defined group of genetically identifiable lines, well-separated and genetically differentiated from the other commercial varieties of barley cultivated in that region. This finding is extremely relevant for the development of a robust, fast and affordable molecular identification assay based on a set of informative microsatellite loci showing marker alleles typical of the Agordino, hence useful for authenticating food derivatives and preventing food mislabelling.

\section{Acknowledgements}

This work was supported by the project 'PROGRAMMA BIO.NET, rete regionale per la conservazione e caratterizzazione della biodiversità di interesse agrario - Gruppo di lavoro cerealicolo (WP5)' funded by Programma di Sviluppo Rurale per il Veneto 2007-2013, Misura 214H, coordinated by Dr. Maurizio Arduin. The authors wish to thank Dr. Mirko Volpato and Dr. Stefano Cherubin for technical assistance with DNA extraction and PCR amplification experiments. Thanks are also due to Dr. Pino Silvio (Istituto di Genetica e Sperimentazione Agraria N. Strampelli, Lonigo, Italy) for providing seed stocks. 


\section{References}

1. Barcaccia G, Molinari L, Porfiri O, Veronesi F. Molecular characterization of emmer (Triticum dicoccon Schrank) Italian landraces. Genet Resour Crop Evol. 2002;49:415-26.

2. FAOSTAT, Food and Agriculture Organization of the United Nations FAO statistical database. Available from: http://faostat.fao.org/.

3. Maresio Bazolle A. The landowner of Belluno (19th century manuscript). In: Perco D, editor. The landowner of Belluno. Feltre, Italy: Pilotto; 1986 (in Italian).

4. Frank R, Jahn F, Barbiani G. Traditional plant from Carinzia, Friuli Venezia Giulia and Veneto. Gorizia, Italy: Regional Agency for Rural Development - ERSA; 2012 (in Italian).

5. Scarano D, Rao R. DNA markers for food products authentication. Diversity. 2014;6:579-96. http://dx.doi.org/10.3390/d6030579

6. Barcaccia G, Volpato M, Gentili R, Abeli T, Galla G, Orsenigo $\mathrm{S}$, et al. Genetic identity of common buckwhaet (Fagopyrum esculentum Moench) landraces locally cultivated in the Alps. Genet Resour Crop Evol. 2016;63:639-51. http://dx.doi.org/10.1007/s10722-015-0273-z

7. Schuelke M. An economic method for the fluorescent labeling of PCR fragments. Nat Biotechnol. 2000;18:233-4. http://dx.doi.org/10.1038/72708

8. Varshney RK, Marcel TC, Ramsay L. Russell J, Röder MS, Stein N, et al. A high density barley microsatellite consensus map with 775 SSR loci. Theor Appl Genet. 2007:114:1091-103. http://dx.doi.org/10.1007/s00122-007-0503-7

9. Applied Biosystems. Peak Scanner ${ }^{\mathrm{TM}}$ software v. 1.0. Thermo Fisher Scientific, Waltham, MA, USA; 2006. Available from https://www.thermofisher.com/order/catalog/product/ 4381867.

10. Nagy S, Poczai P, Cernák I, Gorji AM, Hegedűs G, Taller J. PICcalc: an online program to calculate polymorphic information content for molecular genetic studies. Biochem Genet. 2012;50:670-2. http://dx.doi.org/10.1007/s10528-012-9509-1

11. Yeh FC, Yang RC, Boyle TBJ, Ye ZH, Mao JX. POPGENE v. 1.32: the user friendly shareware for population genetic analysis. Edmonton, Canada: University of Alberta; 1997.

12. Kimura M, Crow JF. The number of alleles that can be maintained in a finite population. Genetics. 1964;49:725-38.
13. Nei M. Analysis of gene diversity in subdivided populations. Proc Nat Acad Sci USA. 1973;70:3321-3. http://dx.doi.org/10.1073/pnas.70.12.3321

14. Lewontin RC. The genetic basis of evolutionary change. New York, NY, USA: Columbia University Press; 1974.

15. Rohlf JF. NTSYS-pc: numerical taxonomy and multivariate analysis system, v. 2.21q. New York, NY, USA: State University of New York; 2015.

16. Falush D, Stephens M, Pritchard JK. Inference of population structure using multilocus genotype data: linked loci and correlated allele frequencies. Genetics. 2003;164:1567-87.

17. Pritchard JK, Stephens M, Donnelly P. Inference of population structure using multilocus genotype data. Genetics. 2000;155:945-59.

18. Evanno G, Regnaut S, Goudet J. Detecting the number of clusters of individuals using the software STRUCTURE: a simulation study. Mol Ecol. 2005;14:2611-20. http://dx.doi.org/10.1111/j.1365-294X.2005.02553.x

19. Doyle JJ, Doyle JL. A rapid DNA isolation procedure for small quantities of fresh leaf tissue. Phytochem Bull. 1987;19:11-5.

20. Jilal A, Grando S, Henry RJ, Lee LS, Rice NF, Hill H, et al. Genetic diversity of ICARDA's worldwide barley landrace collection. Genet Resour Crop Evol. 2008;55:1221-30. http://dx.doi.org/10.1007/s10722-008-9322-1

21. Chen ZW, Lu RJ, Zou L, Du ZZ, Gao RH, He T, et al. Genetic diversity analysis of barley landraces and cultivars in the Shanghai region of China. Genet Mol Res. 2012;11:644-50. http://dx.doi.org/10.4238/2012.March.16.2

22. Khodayari H, Saeidi H, Roofigar AA, Rahiminejad MR, Pourkheirandish M, Komatsuda T. Genetic diversity of cultivated barley landraces in Iran measured using microsatellites. Int J Biosci Biochem Bioinform. 2012;2:287-290. http://dx.doi.org/10.7763/IJBBB.2012.V2.118

23. Bellucci E, Bitocchi E, Rau D, Nanni L, Ferradini N, Giardini A, et al. Population structure of barley landrace populations and gene-flow with modern varieties. PLoS ONE. 2013;8:e83 891. http://dx.doi.org/10.1371/journal.pone.0083891

24. Villavecchia GV, Eigenmann G. New dictionary of marketable goods and applied chemistry, vol. 5. Milano, Italy: Hoepli; 1975 (in Italian). 